These nine cases, which 1 selected from my recent practice, constitute a series of progressive, acute and chronic destruction with extension into the cranial cavity. One case which received no surgical treatment, ended in death by epidural abscess, the other cases, in which timely and sufficient operations were performed, recovered.

\section{THREE CASES OF SUPPURATIVE OTITIS MEDIA; SEVERE SYSTEMIC AND \\ REMOTE DISTURBANCES; RE- COVERY AFTER MASTOID OPERATION AND RE- MOVAL OF POLYPI.}

Presented to the Section on Laryngology and Otology at the Forty-eighth Annual Meeting of the American Medical Association, held. at Philadelphia, Pa., June 1-4, 1897.

BY HIRAM WOODS, JR., M.D.

CLINICAL PROFESSOR OF EYF AND FAR DISEASES, UNIVERSITY OF MIARYAND.

BALTIMORE, MD,

Certain local changes are admitted as indicating need of the mastoid operation. If one or more of the so-called vital indications be present, the demand is emphasized. Apart from these, cases are observed where there is room for legitimate doubt before and after operation; before, because there are no distinotive local signs of pent-up secretion, and yet we see phenomena most easily accounted for by assuming that such a condition exists; after, because no pus is found, and even if the patient recovers, doubt intrudes if operation were really needed to effect cure. The following cases illustrate this fairly well:

Case 1.-John S., age 30, a white laborer, was admitted to the Maryland University Hospital, February 19, 1896. He had been injured the same day by the falling of an embankment. A fractured pelvis was found. $\mathrm{He}$ made an uninterrupted recovery for four weeks, when, the evening temperature, normal for three weeks, rose to 102.5 degrees. He had no pain. The next morning, March 11, temperature was 100 degrees. A bout noon, after a slight chill, there was another rise. Examination did not reveal any cause for the condition observed. During Thursday and Friday the diagnosis of sepsis became clearer, by the occurrence of frequent chilly sensations, fever, increased pulse rate, sweating, loss of appetite, etc. There were no aural symptoms. On Saturday morning the nurse noticed discharge from the right ear. Temperature was 102 degrees; pulse 96 . My attention was called to the man about 1 o'clock. There was no history of previous ear disease. I found pus in the canal, large perforation in the lower anterior quadrant of the drum membrane, Eustachian pervious to both the Valealvan experiment and to Politzerization, and entire absence of pain. The mastoid was neither red, swollen, nor tender. In view of the apparently good drainage from the ear, I decided against operation, believing that it was a case of painless perforation, and the symptoms would now disappear. Treatment consisted in effecting and maintaining cleanlinese. For two days, Sunday and Monday, temperature varied from 99 to 101 degrees. Tuesday evening the man had a chill, followed by a temperature of 103.5 degrees, sweat and prostration. Wednesday the same condition persisted, with the addition of a little redness over the tip of the mastoid. The same afternoon, with temperature 102 degrees, pulse 116, I opened the mastoid under chloroform. The cortex was healthy. The cells were deeply injected, but not more than a drop of pus was found though the opening was continued into the tympanic attic, and a stream of water would pass either way from the ear or mastoid to the other. Recovery was immediate and complete. Temperature reached 101 degrees the day following the operation; but this was the only rise, and the man left the hospital well, May 2.

Case $2 .-$ On January 9, 1897, I saw Josephine N., 6 years old, in consultation with Dr. Thomas McCormick of Baltimore. The child had recovered from scarlet fever three weeks previously. There was a history of acute right otorrhea in infancy. Early in the late illness pain had appeared in the right ear, and had been more or less persistent, though not severe. There had been no discharge. Within the past few days, temperature had become high, after several days of freedom from fever. There was some earache; no more than there had been. Temperature was 100 degrees. The appearance of the canal walls and mastoid was normal. In the drumhead there was the scarred perforation of the former attack. There was, however, no evidence of a tympanic inflammation. Heat was applied for two days, and otorrhea, slight in amount, appeared on the morning of January 11. I did not see the child from the $11 \mathrm{th}$ to the $14 \mathrm{th}$. The attending physician noted scant discharge; elevation of temperature; unrelieved pain. On the 15 th I found the canal walls edematous, so that a view of the drumhead was impossible. A little inoffensive pus was brought out by the cotton pencil. The mastoid was slightly reddened; more, I thought, from heat than any other cause. Temperature was 101 degrees. I thought we had all necessary indications for operation, and so advised. It was declined, and heat, peroxid of hydrogen and syringing continued until the 17th, when, with temperature 101.6 degrees, pulse 130 , local conditions unchanged, operation was accepted. After free incision of the edematous canal walls, and the mastoid periosteum, without finding either pus or a carious point in the cortex, the process was opened, and the opening continued into the attic. No pus was found. Pain was relieved at once; temperature fell to normal, and once during convalescence reached 100 degrees. Otorrhea lasted a few days. The ear hears the watch $1 \% / 8$.

In Case 1 there were septic symptoms for five days, when a painless otorrhea called attention to the ear. In Case 2 there was pain in a formerly diseased ear from the commencement of scarlatina four weeks previous. After some days of normal temperature, fever returned, without increase in the aural symptoms. In both the appearance of otorrhea failed to relieve. Both recovered immediately after the mastoid was opened, and nothing short of this helped. Yet no pus was found, certainly in Case 2, and only a drop, if that, in Case 1. Similar constitutional symptoms occur in the cellulitis of general surgery, and disappear when the infected area is drained, without the presence of pus. The existence of a like primary infection in the mastoids of these patients seems the most plausable explanation of their symptoms.

Case 3.- Prof. Samuel C. Chew of Baltimore, called me in consultation on Nov. 4, 1896, in the case of Mr. P., 27 years of age. For a week Mr. P. had suffered from left frontal headache, with slight elevation of temperature. There was a history of old intermittent otorrhea, and it was to determine a possible connection between the head pain and this, that I was called in. The man was in bed, complaining of agonizing left frontal pain ; temperature 100.8 ; pulse 96 . History showed suppurative otitis dating back to infancy. No systematic treatment had ever been employed. Occasionally $\mathrm{Mr}$. P. washed the ear himself. For five years these attacks of headache had occurred. They were described as sudden, severe, prostrating, and lasting from a few hours to several days. The ear was free from pain, and neither tapping nor firm pressure of the mastoid was resented. The canal walls showed nothing abnormal. A little pus, bad smelling, was found in the tympanum. The drumhead was destroyed, the malleus standing out prominently, thickened, while, apparently attached to the posterior tympanic wall, small polypoid masses could be made out. The patient's family would not consent to operation of any kind. From the 4 th to the 7 th the ear was kept as clean as possible by syringing, and the use of peroxid. There was no increase in the discharge, and little decrease in the pain. Temperature ranged from 99 to 101 degrees. On the afternoon of the 7th the condition grew worse. Pain was agonizing, requiring large doses of morphin to keep the man quiet. I now had doubts concerning the adequacy of any operation about the ear. Pain was absolutely localized in the left frontal region. From the beginning nothing had pointed directly to the ear. True, there was a chronic otorrhea, and inspection showed a state of things commonly observed in old suppura. ting ears; but this was all. That the ear was the primary cause, I had no doubt. That the disturbing factor, whatever it was, had passed beyond the line separating aural from general surgery, I was beginning to believe. A part from waiting for localizing brain symptoms, two procedures suggested themselves, removal of the polypoid growths, and mastoid opera. tion. I had little faith in the ability of the first to relieve the 
symptoms. Not only might the second prove inadequate and leave the patient still in need of cerebral surgery, but such meager indications as there were, pointed to the front, rather than to the rear brain as the seat of disease. I therefere decided to remove the tympanic growths, and if symptoms did not abate, seek a general surgeon's opinion regarding the need of intra cranial exploration. On Sunday morning, 8th, under unsatisfactory cocain anesthesia, I removed the polyps with Buck's curette. Giddiness, profuse sweating, weakness of pulse, and prostration, were the immediate results. Operation was done at 11 A. M., with temperature 99 degrees; pulse 96. At 4 P. M., temperature was 102 ; highest during illness; pulse 120. During the evening respiration assumed a character strongly suggestive, if not actually, of the "Cheyne-Stokes" variety. At first shallow, it became deeper, and passing again in reverse order, ceased altogether for a few seconds, return ing and passing through like a cycle. Pulse rate increased to 140. It looked as though the end was not far off. The ear condition, however, underwent a change. There was a freer discharge of pus. Arrangements were made for operation in the morning, and an early consultation secured with Prof. Tiffany. We found the man still in pain, but his general condition was better than the previous night. Fetid pus discharged freely, and he complained of nausea. Pulse was 76, and temperature 97.2 .

Prof. Tiffany expressed the opinion that this subnormal temperature threw a new doubt into the case. It might mean cerebral abscess. He advised further delay. It proved to be the beginning of convalescence. Within twenty-four hours pain subsided, and the patient was out in a week. Since, the tympanic condition has been treated. In March the ear was dry, and the man apparently as well as ever. There is not much chance of his staying so. Sooner or later he will have another stormy experience. His history indicates that there is a gradual change of some kind going on in his mastoid, probably an accumulation of pus, until a certain point is reached. when the storm breaks. It seems equally clear that there is no organic brain disease. In his case, another attack would call for the mastoid operation, even if it should not be done before; but so remote, and apparently serious condition as existed here, is not, so far as my knowledge goes, a frequent consequence of mastoid stagnation.

\section{Park ave.}

DISCUSSION ON PAPERS OF DRS. KNAPP AND WOODS.

Dr. SEIss-Out of my last 4300 cases, only 85 were mastoid. Out of these there was only one death, and that was the only case where any more extensive operation was done than removal of the outer table.

Dr. RaNDALL-To know what constitutes disease of the mastoid is esesential. Where we have decided swelling, redness and pain over the mastoid region with tenderness to pressure, together with acute inflammation of the middle ear, I call it acute inflammation of the mastoid. I see many cases brought to a successful issue after operation. I have seen quite 100 of these cases every year, and but a small proportion come to operation. I have done as high as thirty mastoid operations in a year, all with pus freely present over the mastoid. In at least one-half of my recent cases the inner table has been broken down, pus was present on the dura, and pachymeningitis more or less present. In the last Stacke operation which I did, I found it imposeible to determine where the dura lay. It was covered with flabby granulations, and in removing these with a curette I stopped short because I found I was removing brain tissue. The patient was not hurt by this blun der, so far as I could discover, but it shows that we must be careful. In these cases I can not feel as a general thing that I have done too much. I can not always get complete healing by radical measures, and it is perfectly fitting for those who hold more conservative views to hold them in spite of all that I can say, The majority of mastoid cases can get well without operation and not be in the slightest degree worse for the delay. Last year I had 500 cases; others might say that they were not mastoid cases at all. I can not give only one death in 85 cases, but I have but one death due to operation in 135 cases. One or two died of pneumonia or brain disease, absolutely uninfluenced by the operation.

Dr. Woods-I am aware that the first two cases I reported are open to criticism as to whether they would not have done just as well without operation. The knowledge of that fact led me to report them. There were no local symptoms of mastoid disease, save the slight redness mentioned; and yet, with a history of acute otorrhea in the first, old suppurative otitis in the second, and temperature characteristic of sepsis in both, operation seems to me the safest treatment.

Dr. Laurence Turnbull-I would like to ask Dr. Knapp as to neuralgia of the mastoid. I know of a case where a young girl passed a bead into the mastoid. It gave no uneasiness at first, but later there was discharge and pain. She came to the Jefferson Hospital with this peculiar neuralgic pain gravitating toward the mastoid, and after cleansing the ear we opened the mastoid and left the bone clean and white. . She seemed to be improving for a time, but later returned several times with the intense pain. The mastoid was finally opened a second time; but she still has the pain.

Dr. KNAPP-I have found mastoid neuralgia in cases where a chronically inflamed mastoid is undergoing conversion from the pneumatic and diploic varieties into the sclerosed. When we operate for this condition we mostly find the mastoid compact and, in some layers at least, usually the medial ones, congested. These cases get well by operation, and in time, also spontaneously, I think by destruction of the nerve either by the operation or by compression during the sclerosing process.

\section{WHAT CAN BE ACCOMPLISHED BY TREAT- MENT OF EUSTACHIAN TUBE,}

WITH SPECIAL CONSIDERATION OF THE TREATMENT OF CHRONIC STENOSIS.

Presented to the Section on Laryngology and Otology, at the Fortyeighth Annual Meeting of the American Medical Association, held at Philadelphia, Pa.. June 1-4, 1897.

BY GEORGE MORLEY MARSHALL, M.D.

LARYNGOLOGIST AND OTOLOGIST TO ST. JOSEPH'S HOSPITAL; LA RYNGOLOGIST TO PHILADELPHIA HOSPITAL.

PHILADELPHIA, PA.

Let us briefly recall the anatomy and function of the Eustachian tube, in so far as it concerns the measures advocated in this paper. The Eustachian tube is the passage between the naso-pharynx and tympanic cavity -in length thirty-three to forty millimeters. From its relatively large pharyngeal mouth it extends twenty-five millimeters with walls formed by an incomplete furrow of fibro-cartilage, consisting of a posterior and anterior plate, the anterior being movable. This portion of the tube where not cartilaginous is membranous, which with its lining mucous membrane has considerable thickness. This cartilaginous portion of the tube unites with the remaining ten to fifteen millimeters of the osseous portion of the tube, forming with it an obtuse somewhat circular angle of 135 degrees. At this angle the lumen of the tube is smallest; that is two to three millimeters.

The walls of the Eustachian tube are lined by glandular mucous membrane, with ciliated cylindric epithelia, whose ciliary movement is directed toward the pharyngeal opening which has a lower level than the tympanic opening. The lining of the osseous portion is smooth and closely incorporated with the periosteum. With surrounding conditions normal, the normal Eustachian tube allows the passage of air not with absolute freedom, for the tube at rest has its sides in contact, but yet with sufficient freedom to establish an approximate equality of atmospheric equilibrium, allowing the secretions of lining membrane of the tube and tympanum to escape or evaporate. But if atmospheric pressure is not approximately equal the air in the tympanum is absorbed by surrounding liquids through the walls of blood and lymph vessels, obeying the law that liquids absorb their own volumn of associated gas, and thus the air not being renewed in the tympanum, there follow the 